\title{
Cognition, Governance and Participation: The Rise of Community Leaders Under the Model of "Point Bank"
}

\author{
XIE Yi-Shuai ${ }^{1, *}$, LIU Ke-Hong ${ }^{2}$ \\ ${ }^{1,2}$ School of management, China West Normal University, Nanchong, Sichuan 637009, China \\ *Corresponding author. Email:953827260@qq.com
}

\begin{abstract}
"Point Bank" is an innovative model of community governance. Due to different interpretations of social governance concepts and community charity organizations, as well as frequent changes of grassroots governance institutions, community leaders' self-participation in community governance is affected by the friction between "benevolence" and "points". Some backbones, unable to integrate into the "Point Bank" model, are actively or passively trapped in multiple difficulties. Therefore, it is necessary to correct the misinterpretation of the concept of grassroots governance, explore the path of community public welfare and charity organizations, and enable community leaders to lead residents to use "points to leverage co-construction and co-governance".
\end{abstract}

Keywords: Community governance, Point Bank, chemistry, Community leaders

\section{INTRODUCTION}

This paper makes a general analysis and limitation on the construction of community leaders under the "Point Bank" model from three dimensions of cognition, governance and participation. First, cognition refers to the emotional factors of community leaders themselves. These traditional ways of thinking and behavior affect community leaders' participation in community governance. Second, governance refers to the interaction of multiple subjects under the current governance model. The economic and moral elements contained in "point bank" directly act on community leaders. The third is participation, which refers to the achievable path of community governance, that is, how to promote the participation of community residents, explore human resources and cultivate community leaders.

\section{COGNITION: The Alternation Of Rational And Irrational Factors}

In the process of understanding objective things, there are two kinds of psychological intuitive reflection: rational factors refer to human intuition, thinking and other abilities, while irrational factors mainly refer to human emotion, will and other activities. Rational studies mostly position community leaders as a tool or means of community governance, focusing on the scientific, professional and inhuman construction of community organizations, while irrational studies introduce the emotional factors of community leaders into the field of community governance, focusing on mobilizing the subjective initiative of people and giving play to their spontaneity.

\subsection{The limitation of rational factors}

In the field of grassroots governance in China, the way of community governance is relatively rational, which mostly influences the daily operation of streets and communities through administrative policies. The awe of traditional bureaucratic thoughts subtly interferes with the habit of community residents to participate in community governance. Nowadays, the concept of irrationality has been generalized. In the past, we used to recognize irrationality with a negative connotation[1]. In order to avoid one-sided interpretation, this paper expounds the rational factors of community governance, and then discusses the internal relationship between the irrational factors and community leaders:

Firstly, the standardization and institutionalization of community governance can explore the pioneer strength of the community. Community leaders are influenced not only by socialist politics, economy and culture, but also by different family backgrounds, learning experiences and personal lives. Governance model of general laws of development of community already gradual change, also have some emergencies caused by leap type development, therefore under the community service projects, community volunteer service of short-term or do not continue, may cause unstable, community leaders cultivate only after a long motivation could regulate community leader behavior.

Secondly, community leaders should emphasize both results-oriented working methods and process objectives. Under the leadership of the community Party committee, community leaders mainly cooperate with the community to solve problems according to the basic conditions of their communities and the achievements in the reform of community governance. Community leaders lead social workers, young workers, old people and children to tie numerous individuals into a knot and twist them into a 
rope. Community leaders also have certain purposes in the process of volunteer service, and they should appropriately guide community leaders to positively move towards the expected virtuous and good track, and arouse the hidden moral nature in their hearts. Of course, it may be difficult to operate.

Thirdly, to explore and cultivate community organizations, it is necessary to combine the strength of community leaders such as volunteer backbones and self-organizing leaders. Staffing and resource integration are both mandatory issues in the process of community governance. The former is to guide residents to participate in community affairs with the help of community leaders, improve the community organization system, and build a multi-subject linkage mechanism. The latter is because community leaders have close contact with community residents, and they can patiently explore and cultivate hidden social organizations in the community, so as to develop those with strong planning and organizing ability as community organization leaders.

\subsection{Irrational Factors and "Point Bank"}

Irrational factors emphasize individual values, social outlook and world outlook, pay attention to the differences between people, and tend to subject psychological activities. Bertrand Russell has said, "To those who accept a king, the ordinary obedience of the majority of his subjects is at first the result of fear, and then of custom and tradition." Different community residents individual appeal is not the same, strict control from the irrationality of the traditional community management requirements, and a variety of management and service concept in ideological trend, under the impact of some community leaders began actively relations on behalf of the size of the transaction, rather than passively obey and accept, based on the interpretation of irrational factors make the following:

Firstly, has a lot of irrational factors and community leaders directly related, such as coastal areas of voluntary service for community residents or in some community of social workers, volunteers and residents of the individual, set up "Good Banks" public welfare charity, on the basis of the demand for an organization helping each other, from "them" become "we". Some of them are indirectly related to it, such as the "Point Bank" described in this article. With the help of this platform, the enthusiasm, initiative and creativity of community leaders to participate in grassroots community governance are maximally mobilized, so as to create a community in which all the people participate in community governance.

Secondly, the influence of irrational factors on community leaders is two-sided. "Point Bank" establishes the mode of "governance + service" and the path of "all for one, all for one", which can help to stimulate the inner "truth, kindness and beauty" of the backbone of the community, give full play to the wisdom of leaders, gather the strength of leaders, and guide the service concept to fit with the mainstream values. However, letting community leaders deposit their volunteer services in the bank in the form of points may induce hypocritical behavior, which is contrary to the moral quality advocated by good deeds. Even the neighborhood relationship will become more utilitarian, leading to the hollowing out of community volunteer service.

Thirdly, there are differences in the degree of influence exerted by irrational intensity on community leaders and other governance bodies. The quality of the community environment has a positive and negative relationship with the development of community leaders. A relatively loose community atmosphere is also conducive to the growth of community leaders. However, a bad community environment may weaken or expand residents participation in community governance. The community hopes to grind the community representative groups into a joint, co-governance and sharing position that is down-to-earth, close to the hearts of the people, and gather popularity. In the later stage, it will focus on the cultivation of community leaders and the performance of their functions of participation in discussions.

\section{GOVERNANCE: Friction Between "Good Works" and "Points"}

In the implementation process of "Point Bank", there are complex rational factors and irrationality. To analyze the influence of this type of community service mode on community leaders, it is necessary to break the situation of single separation, combine economic and ethical perspectives, and reposition the mechanism of exchanging points for volunteer service. The model of "Point Bank" does not ignore the economic elements, but also contains ethical elements, which can be verified at least from the following contents:

\subsection{From an Economic Perspective}

The connotation and operation of "Point Bank" contains rich economic elements. When propagating to community leaders, it should be clearly explained that it is obviously different from the commercial Banks with which people come into contact at ordinary times, and problems should not be considered with the fixed thinking mode of "the antinarlaw" between morality and economy. Points also involve the vested interests of some community leaders, such as building sanitation, road cleaning, community greening and community convenience affairs, which ultimately lies in the general convenience and benefit of the people service and "points" tied together, the leaders have less than one appearance, to serve the community residents for points. Can human goodness really be measured? Some scholars hold a skeptical attitude towards the measurement unit, mode and operation system of benevolence[2]. Community volunteer service itself is a kind of good, it is difficult to use measurement tools to measure its real value, it is also unable to carry out complete statistics and test.

"Point Bank" can store the points obtained through 
voluntary services, which is in line with the actual situation of the socialist market economy. In order to save funds and meet the requirements of the relevant financial budget system, the "Point Bank" implements an annual point system, and all points not redeemed by users will be donated to the "Point Bank" every year. Only on a quarterly basis, a scoreboard is set up to award the top few in quarterly service and reward them with corresponding points. For the other community leaders who are keen on community volunteer service, the incompleteness of this evaluation index makes their participation enthusiasm frustrated. At the same time, the curriculum of the community party and mass school has a large scope of radiation, lacks the ability to cultivate and improve the backbone of the community, and lacks the pertinence to the main force of community governance.

Besides those spiritual incentives, the points stored in the "Point Bank" also include these economic incentives, which not only enable the community leaders to see the tangible "benefits", but also satisfy the honor that the leaders desire. Appropriate material rewards and spiritual care should be given to ensure the reasonable rights and interests of community leaders to participate in voluntary service. If the behavior of the community backbone cannot be recognized and effectively motivated within the points-based system, it will lead to the failure of the model. At present, the point exchange of "Point Bank" is mainly based on objects such as daily necessities. Such material incentives are necessary, but they ignore the spiritual consolation of community leaders, which makes community leaders fall into the dilemma of self-motivation, recognition and management, leading to the chaotic situation of the implementation of "Point Bank".

\subsection{From the Perspective of Ethical Thinking}

The existence of moral bank accords with the public's pursuit of moral ideals, not only conforms to the advanced thought and theory of Marxism, but also conforms to the characteristics of China's socialist construction at the present stage. It is a bold combination of ideology and economy[3][3]. Current "Point Bank" does not simply copy the mode of economics, though still is aroused by maximize the benefit of the moral community leaders from the good heart, but its operation, service and guarantee mechanism initially formed their own characteristics, the implementation of the "Point Bank" course, the role of community leaders also more and more nots allow to ignore, respect the personalization features of community leaders, way, living habits, such as mining leaders to participate in volunteer service activities of true feeling, invisible community volunteer service hours into integral physical, let the leaders of the hard work can clear display, Keep leaders motivated to volunteer on a continuous basis.

As an innovative initiative of grassroots governance, "Point Bank" contains several innovative elements in its score standards. The existing data of points and savings may not reflect the real situation of governance in the community, but to a certain extent can assess the moral construction of community leaders. How to explore the balance between community-level governance, voluntary service activities and community leaders' participation, so as to keep the residents' ethical and moral concepts advancing with The Times? Cultivating community leaders and incubating autonomous organizations should not only popularize the knowledge of points in daily life, which is not the first direct element of service, but really mobilize the pioneer exemplary role of community leaders. Of course, we can't deny the economic idea of exchanging points for volunteer service. "Do it or not" and "how to do it" community volunteer service should be measured by leaders' choice. Leaders' self-will should be affirmed and the trajectory of community activities should not be easily deviated from.

In ancient China, there was a simple thought of "good will be rewarded with good, and evil will be rewarded with evil". If the current community volunteer service points are guided solely by the principle of "input -benefit", it will lead to moral misunderstanding, moral entanglements and finally moral kidnapping[4]. If only the monetary form is used to measure the quantity or quality of good deeds, it will lead to the falsity of community volunteering service and the hollowing out of community governance as a whole. Each community regularly carries out honorary title selection activities such as "Community Good person", excavates those who have passion for community construction and are willing to spend time and energy, guides community leaders to make contributions to community service, and enhances leaders' sense of belonging and security to the community. This practice encourages and strengthens the real and inner kindness, and reduces the behaviors of rewarding points and damaging the real voluntary service. These experiential participatory governance methods shape the governance legitimacy of community leaders.

\section{PARTICIPATION: The Relationship Between Community Leaders and Co-governance}

As a community governance model of co-construction, co-governance and Shared benefits, "Point Bank" is still in the exploratory stage. Although various local departments actively carry out pilot work, many difficulties are inevitable. With the awakening of residents' consciousness and the rise of backbone forces, there will be more ideas on grassroots governance in this regard. This paper puts forward the following thoughts on the future development of community leaders:

\subsection{Encourage Ccommunity Leaders to Participate in the Work and Inject Fresh Vitality into the Community}

The important step for community residents to become community leaders is to participate in community organization work, give full affirmation to community leaders, inspire the spirit of being masters, establish the 
consciousness of independence and self-reliance, and cultivate the leadership style of equal mutual help discussion, effective communication and respect for the majority with residents. By institutionalizing and standardizing the construction, it breaks the previous situation of inconsistent service modes and incentive standards among different communities within the jurisdiction, and unifies the score value standard and service record mode, so as to make the management of community volunteer service more fair and transparent and improve the management efficiency of volunteer service. We will mobilize the enthusiasm, initiative and creativity of community leaders to participate in community-level governance, and build a community in which all the people participate.

Build clear, good, help each other between various main bridge, using the mobilization of community leaders and executive ability, "Point Bank" operations can constantly inject fresh vitality, motivate residents volunteer to provide community service, enrich the existing service power, through the integral circulation promoting residents participate in community, work, and sharing. Social situation and public opinion will be conveyed through innovative channels. WeChat public platform and resident service group will be used online, and on-site visits of community leaders will be used offline to organically combine "online + offline" to effectively solve the problems of community residents. Community leaders provide online and offline services. With the help of the Party and mass school platform, community Party and mass schools provide brand building services for "community leaders". They keep doing the service of The Party and mass school in fumin community to build a good reputation among residents.

\subsection{Cultivate the Mutual Assistance Behavior of Community Leaders and Form the Habit of Community Governance}

Through the study of various courses, community residents are guided to participate in party and mass schools, and during the learning process, residents who are enthusiastic and positive, have strong growth motivation and are willing to continue to grow are explored and selected, laying a good foundation for the establishment and cultivation of community leaders. Develop the training and exhibition service of community leaders, constantly provide opportunities for community leaders to learn, enable community leaders to have skilled skills and abilities, set courses in the community or apply their abilities to community service, gradually mature operation and continue to include new social leaders. To avoid low work efficiency caused by unclear rights and responsibilities of community leaders and unclear division of labor, a regular training mechanism for community leaders should be established to realize the standardization, institutionalization and long-term effect of community cadre training and education. Guide the community multi-service team to combine with the "Point Bank" points standard to form a benign interaction of community residents' autonomy.
The party and mass schools "endorse" the community leaders, and the community leaders "empower" the party and mass schools, while the "Point Bank" encourages the community leaders to participate in the voluntary service with its unique service mode, and obtain the corresponding points by accumulating the service hours, and exchange the points for different goods. With the operation mechanism of "Point Bank" as the incision point, community volunteer service resources are integrated to make the management of community volunteer service more fair and transparent and improve the management efficiency of volunteer service. Build clear, good, help each other between various main bridge, using the grass-roots mobilization and implementation ability, "Point Bank" operations can constantly inject fresh vitality, encourage community leaders actively ran up with new ideas, enrich the existing service power, promote leaders involved in the community by integrating circulation, work, and sharing. Meanwhile, the emerging community activists should play a more important role in community governance by tapping their potential.

\subsection{Excavate and Cultivate Community Leaders to Improve the Level of Community Service}

Community co-construction and co-governance cannot be separated from the active participation of community leaders. Targeted capacity training should be carried out for community residents to guide them to participate in community governance. Combined with the strength of community social workers and community leaders, we will patiently explore and cultivate hidden social organizations in the community, and intend to develop residents with strong planning and organizing ability to become leaders of community organizations. Through consultation and consultation, we will establish a team of co-construction, co-governance and sharing, so that community backbones, leaders and enthusiastic community development personages will become the core force and spokesperson of community-level governance. Women in the community are also an indispensable force in community governance at the grass-roots level. Women leaders in the community should be explored and platforms such as community women's conference and symposium should be fully utilized to play the role of "living water" and pay attention to the vital interests of community residents.

"Point Bank" can dig out people who are enthusiastic about community construction and willing to spend time and energy to build, jointly rule and share human resources for the community through the ranking of multiple points and the selection of honorary titles such as "Community Good person". By virtue of the example power of the scoreboard, the effective allocation of community resources can be improved, the integration and exchange of community information can be realized, 
the man-machine support network service of community young workers can be deepened, and the sense of belonging and security of community volunteers can be enhanced. To become a qualified community leader, one needs to go through comprehensive and systematic volunteer training and participate in community volunteer service for many times. Only in this way can one transform from a group of volunteers into a backbone member and then become a good helper in managing community affairs.

\section{CONCLUSION}

Such charity and public welfare organizations as "Point Bank" combine their own characteristics to explore the moral construction platform and logic new mode needed to adapt to the new social situation. They have not only the part where the role positioning of community leaders is unclear due to the participation motive, but also the practical experience derived from grass-roots community governance. It may be one-sided, but it is by no means useless.

\section{ACKNOWLEDGMENT}

This work was supported by the research center for the Development of Grass-roots Health Undertakings in Sichuan Province (SWFZ16-W-04) and the Undergraduate Innovation and Entrepreneurship Training Program (CXCY2018116).

\section{REFERENCES}

[1] Zhang Aijun. Irrationality: A New Perspective of Socialist Democracy research . Journal of Dongbei University of Finance and Economics. 06(1999)68-71. DOI:https://kns.cnki.net/KCMS/detail/detail.aspx?dbcode $=\mathrm{C}$ JFD\&dbname $=$ CJFD 9899\& filename $=$ DBCD199906017\&v =MDczMTFvRmlEbVVyL01JUy9JYXJLeEY5ak1xWTIFW TRSOGVYMUx1eFITN0RoMVQzcVRyV00xRnJDVVI3c WZZT2Q=

[2] Lin Xuanlong, Liu Huafang. Review of negative Effects of "Moral bank" . Teaching and Management. 02(2014)4-5. DOI:https://kns.cnki.net/KCMS/detail/detail.aspx?dbcode $=\mathrm{C}$ JFD\&dbname $=$ CJFD2014\&filename $=$ JXGL201402003 \&v $=$ MTY1NjF6WE1Zckc0SDIYTXJZOUZaNFI4ZVgxTHV4W VM3RGgxVDNxVHJXTTFGckNVUjdxZllPZG9GeW5oV mJyT0w=

[3] CAI Xinxin. Expectation of Citizen's Moral Return -Analysis of "Moral Bank" Phenomenon . Journal of Social Science of Shanxi University. 12(2007)12. DOI:https://kns.cnki.net/KCMS/detail/detail.aspx?dbcode $=\mathrm{C}$ JFD\&dbname $=$ CJFD2007\&filename $=$ SXGD200712042\&v $=$
MjYyOTBiTnJZOUJab1I4ZVgxTHV4WVM3RGgxVD NxVHJXTTFGckNVUjdxZllPZG9GeWprVXJ6Qk5qW E1hckc0SHQ=

[4] Shi Yiman. Construction of "Moral bank" from the perspective of ethics . China Youth Research. 04 (2012) 108-110.DOI:https://kns.cnki.net/KCMS/detail/detail.asp $\mathrm{x}$ ?dbcode $=$ CJFD \&dbname $=$ CJFD2012 \& filename $=$ ZGQL 201204020\&v=MTk3NzRxVHJXTTFGckNVUjdxZ11PZ G9GeWprVUx6Q1B5cmFZckc0SDIQTXE0OUhaSVI4Z VgxTHV4WVM3RGgxVDM= 